\title{
Ethno-Ornithology of the Mushere of Nigeria: Children's Knowledge and Perceptions of Birds
}

\author{
Grace Pam ${ }^{1 *}$, David Zeitlyn², Andrew Gosler ${ }^{1,2}$ \\ ${ }^{1}$ Edward Grey Institute of Field Ornithology, Department of Zoology, University of Oxford, UK. ${ }^{2}$ School of Anthropology and \\ Museum Ethnography, University of Oxford, UK. \\ *grace.pam@zoo.ox.ac.uk
}

\begin{abstract}
Mushere children's ethno-ornithology was surveyed from October to November 2015 to find out their level of bird knowledge-as well as whether and how children valued and learned about birds -in order to determine the potential role such knowledge might play in Mushere biodiversity conservation. Methods included picture elicitation exercises, freelisting, and semi-structured interviews. Our results revealed a limited knowledge of birds in Mushere children, and that bird knowledge was gendered. Girls learned through observation, while boys learned through practical bird-related activities. Learning was mostly horizontal for boys but vertical and/or oblique for girls; the most reported learning mode was through oral tradition. Farmland and garden birds were the most common groups, with birds in the families Columbidae and Estrildidae having the highest salience and frequency of mention. We suggest that this reflects the importance of ecological salience, since both groups are relatively locally abundant. The children also had a limited knowledge of cultural beliefs and uses of the birds, but valued birds as important. We argue that how much children will know and learn about any biological domain will be determined by the cultural attitudes and perceptions of that domain, and the cultural importance attached to it. We conclude that the limited knowledge of birds in Mushere children reflects Mushere cultural indifference (ornithoapatheia) to birds. We suggest that a consistent and deliberate conservation education program that will work towards encouraging ornithophilia, the love of birds, and biophilia, the love of nature, in Mushere children could be beneficial.
\end{abstract}

Received March 14, 2017

OPENӘACCESS

Accepted September 27, 2017

DOI 10.14237/ebl.9.2.2018.931

Keywords Ethno-ornithology, Mushere, Children, Ornithoapatheia, Biodiversity conservation

Copyright (C) 2018 by the author(s); licensee Society of Ethnobiology. This is an open-access article distributed under the terms of the Creative Commons Attribution-NonCommercial 4.0 International Public License (https://creativecommons.org/licenses/by-nc/4.0), which permits non-commercial use, distribution, and reproduction in any medium, provided the original author and source are credited.

\section{Introduction}

The conservation of biodiversity has gained impetus in recent years as one of the greatest global concerns through the creation of the United Nation's Convention on Biological Diversity (CBD) in 1992, the UN declaration of the year 2010 as the international year of biodiversity, and the years 20112020 the decade of biodiversity (UN 2011). However, the effectiveness of conservation action in any location depends largely on how interested local people are in nature, their terms of engagement with it, and their level of environmental literacy (Hunn 2002). As the hope and future of any society, and the future custodians of the earth, children are an essential focus for conservation education and engagement. How children perceive the world around them is, therefore, crucial to the role they will play in the future when they are faced with the challenges and responsibilities for its management (Hunn 2002). Many studies have shown that children's environmental knowledge is declining as more children spend time away from nature (e.g., Charles and Louv 2009; Louv 2008; Medin et al. 2006; Singer et al. 2009), resulting in a number of behavioral, emotional, and psychological phenomena which Louv has collectively termed Nature Deficit Disorder (Louv 2008). While one might expect this phenomenon to be more widespread in urban settings and less in rural areas (see Tuan 2012), study after study is revealing the same pattern of knowledge loss in children in both urban and rural situations (e.g., Clements 2004; Cruz-Garcia 2006; Somnasang and Moreno-Black 2000). As Turner et al. (2000) observed, young people 
in many cultures nowadays are far less knowledgeable about their traditional ecological knowledge (TEK) because modes of transmission of knowledge have been threatened by changes in lifestyle. Within a theoretical framework of ethnobiology, however, folk naming and classification may be driven by ecological and other kinds of salience (Gosler 2017, Hunn 1999), in addition to the perceptions and connectedness of a people to nature.

Given the significance of birds in promoting biodiversity conservation, we set out to assess the potential of using children's ethno-ornithological knowledge as the foundation for encouraging children's engagement with nature and participation in its conservation. Most studies relating to children's ethnobiological knowledge have centred on their ethnobotanical knowledge (e.g., Cruz-Garcia 2006; Guimbo et al. 2011; Martinez-Rodriguez 2009; O'Brien 2010; Quinlan et al. 2016; Wyndham 2010; Zarger and Stepp 2004). Few studies have looked specifically at the ethno-ornithological knowledge of children (see Bonta 2003) and, to the best of our knowledge, none exist that focus entirely on ethnoornithology of children; we hope to contribute in this area. There is good evidence that the close association with nature found in many cultures around the world often translates into children having considerable TEK of plants and animals at a young age. For example, the Tzeltal-Maya of Mexico are known to have great depth of knowledge of their plants and animals, with their children knowing over 100 plant names by the time they are nine years old (Casangrade 2004; Hewlett and Cavalli-Sforza 1986; Hunn 2002; Quinlan et al. 2016; Stross 1973; Zarger 2009, Zarger and Steppe 2004).

In addition, the Mushere people's relationship to their flora and fauna has not been studied or reported previously, especially with regards to children's local environmental knowledge; we hope to make a contribution in this area also. Understanding the human-environment interactions in all habitat types and societies is important for better understanding and conservation of the world's biodiversity. As Daugherty (1978) observed, the importance of a domain to people depends on how much importance and attention, or indifference, they give to that domain. In this paper, we report on the bird domain as it is perceived and valued by Mushere children and discuss the implications of these findings for nature conservation. Our earlier study on Mushere ethno- ornithology (Pam et al. in prep.), revealed an indifference towards birds, which we termed ornithoapatheia, contrasting with Bonta's (2003) ornithophilia and ornithophobia hypotheses (also, Peintner et al. 2013; Wasson and Wassson 1957). It is difficult to know how widespread such an indifference to birds is in Nigeria due to limited data. However, a study conducted in Kwara State, Western Nigeria by Weliange et al. (2015) reported a relatively rich ethnoornithological knowledge relating to the cultural significance of birds. Although the actual number of species recognized in that study by locals was only twenty, they reported a richer cultural knowledge among the yorubas of the south-western part of Nigeria held in their folklore, proverbs, and rituals.

Our studies with the Mushere led to the present research on Mushere children's ethno-ornithological knowledge. In particular, we wanted to understand the place of birds as perceived by Mushere children. The central question therefore was: Is bird knowledge children's knowledge? If so, how might it be used to encourage nature conservation in Mushere? Also, since understanding how children learn is important (Zarger 2009), we also ask the following questions which are pertinent to the understanding of the cultural transmission of knowledge: What are the methods/modes of TEK acquisition and transmission among Mushere children? What factors influence the acquisition and transmission of TEK? How does children's knowledge differ from adult knowledge? Finally, we ask, what birds do Mushere children know and why?

Elsewhere in the world, birds have successfully been used to foster a conservation ethos and to encourage participation in conservation. Since, for example, Birdlife International and its partners in different countries around the world have successfully advocated for biodiversity conservation through birds (e.g., Williams et al. 2014), it is easy to assume that birds will be favored everywhere. However, developing a genuine partnership in a communityparticipatory project necessitates that conservation practitioners work with what the people already know and value. Nigeria has been reported as one of the countries in Africa with more traditional uses of birds (Cocker 2000; Nikolaus 2000; Williams et al. 2014); how do these uses translate in terms of cultural bird valuing? As Bonta (2003) observed, a conservation project could miss a lot by not recognizing the thoughts and feelings of locals towards their avifauna. 
Might children differ from adults in their perceptions and valuing of birds, and perhaps even exhibit more local knowledge of birds? Indeed, there might be a special relationship between children and birds that tends to fade with adulthood (Bonta 2003; Cobb 1969). If this were indeed the case, conservation action might be most readily effected through children's education.

\section{Methods}

Mushere is in the Bokkos local government area of Plateau state, north-central Nigeria. It is located at $9^{\circ}$ 9' 0" N, 9 3' 0" E, across a total land area of 870.25 $\mathrm{km}^{2}$, with an estimated adult population of 37,000 residing mostly in fourteen Mushere villages. The Mushere are one of the tribes occupying the southern side of the Jos Plateau. The northern part of their tribal area is on the open high plateau at around 1200 $\mathrm{m}$ ASL, while the southern part extends through the maze of hills and valleys through which the plateau descends to the Benue Valley lowlands in the south, at about $300 \mathrm{~m} \mathrm{ASL}$ - there is no escarpment in this area. The Jos Plateau has a considerable effect on rainfall in areas adjacent to it. The western edge and nearby areas have considerably higher rainfall than other places in Nigeria at the same latitude, with a tendency for a slightly longer rainy season. This means that forest naturally occurs within this belt, which extends round to the western part of the southern edge of the plateau. This is not merely gallery forest, as is found elsewhere at this latitude, and most land within this belt is southern guinea savannah. The Mushere practice a subsistence farming culture; the main occupation of the Mushere people is agriculture, growing millet (Pennisetum glaucum), Fonio (Digitaria sp. [locally called accha]), maize (Zea mays), guineacorn (Sorghum bipolar), and sesame (Sesamum radiatum). A few parents of the children we studied also worked as civil servants in addition to farming and had at least a primary school education. The predominant religion of the Mushere is Christianity, although a few older individuals are traditionalists (Mushere et al. 2007). The Mushere are an understudied group, and published information concerning their history is scarce.

Students were selected from across six Mushere secondary schools who were in their first, second, or third years of secondary school, and between the ages of 12 and 15 years. All respondents claimed to be Christians. We interviewed 56 secondary school children from three Mushere communities (Garah,
Kawel, and Ik'ngwakap). Other research has shown that by this age, children are able to attain an average adult level of competency in their knowledge of plants and animals (Cobb 1969; Hunn 2008; Kreutz 2015; Wyndham 2010; Zarger 2002). In addition, individuals in Mushere culture are considered children up to the age of 15 years, and an adult capable of raising a family from the age of 16 onwards. Furthermore, our decision to limit participation to this age group was based on prior knowledge working with children during our time in Mushere. We found that children under the age of 12 years could not make meaningful contributions as they were very shy, and were not able to communicate freely with the researchers, probably due to language barriers and their low level of exposure to "strangers". Wyndham (2010) made similar observations in her work with Rarámuri children, observing that children who attended school were more confident and willing participants in her research than those who lacked any formal schooling, with some of them declining to participate in her research.

The interview environment was a classroom in each of the participating schools, where we were supplied with a table and chairs where we interviewed each respondent. Using semi-structured interviews, we collected information on their socio-demography, free -lists of birds, TEK of birds, as well as bird-related Mushere stories and songs. Free listing is important in finding out where to concentrate effort in applied research (Bernard 2000). It also has the advantage of giving the researcher a good picture of the overall perceptions, or knowledge, of a domain using relatively few respondents. A purposive sampling technique (Bernard 2000; Tongco 2007) was used in selecting participants. This deliberate, non-random, non-probability approach allows the researcher to select participants based on predetermined criteria that fit the purpose of the research (Bernard 2000). In our case these included a willingness to participate in the research, individuals who possessed some knowledge of birds, and lastly, those who had the ability to communicate and share their knowledge of birds.

Using a picture elicitation exercise (Bignante 2010; Epstein et al. 2006; Kellert 1984; Si 2016; Weliange et al. 2015), in which each respondent was shown a colored picture of a bird, we asked each respondent to identify twenty-two bird species previously recognized from the adult free-lists as culturally salient. We were 
Table 1 Free-list results of children's most salient bird species (See Table 2 for identification).

\begin{tabular}{llll}
\hline Item & Frequency (\%) & Average Rank & Salience \\
\hline Mbul & 92.9 & 2.60 & 0.75 \\
Tidit & 78.6 & 3.02 & 0.60 \\
Mbulkan & 57.1 & 5.38 & 0.28 \\
Fyem & 46.4 & 5.50 & 0.23 \\
Yiyi & 41.1 & 5.53 & 0.19 \\
Nayakar (Kwom) & 39.3 & 4.23 & 0.24 \\
Ngupiya & 37.5 & 5.81 & 0.16 \\
Nilip & 35.7 & 5.00 & 0.17 \\
Yerkong & 35.7 & 5.95 & 0.16 \\
Yerdang & 32.1 & 5.17 & 0.17 \\
Njakan & 30.4 & 5.35 & 0.16 \\
Nanaan & 28.6 & 5.69 & 0.13 \\
Canary & 23.2 & 3.46 & 0.16 \\
\hline
\end{tabular}

careful to ensure that pictures were of high resolution and quality, and that children had no trouble recognizing two-dimensional images. We interviewed each respondent in isolation, to ensure privacy and independence in answering questions. All interviews were conducted in Hausa language with our Mushere interpreter translating into Mushere any aspects that seemed unclear to a respondent. All respondents were bilingual, speaking Mushere and Hausa languages, with most also able to communicate in English. All scientific bird identifications and naming followed the Birdlife International guidelines (BirdLife International database, 2017).

The time spent with each child during interviews was 30-45 minutes. The interview protocol involved using the first three minutes learning about the background of the respondents, and giving information on the general procedure for the exercise. This helped them become better settled for the interview, which many first approached like an examination situation, showing some nervousness. By emphasizing to the children that we were eager students, willing to learn about their relationship and knowledge of birds, we put them in the teacher's position, a method that proved effective by making them more relaxed and settled for the interviews.
Respondents were also asked to share everything they knew and could recall about the local bird names, ecology, uses, cultural beliefs, stories, and/or songs related to each bird. The responses were written down in our field data sheets and later transferred into an Excel spreadsheet, making sure that each respondent had a unique identification code. Results of the children's free-lists, which were analyzed using the Anthropac 4.0 software (Borgatti, 1996), are presented in Table 1.

Recognition scores were assigned to each child for every bird identified ( 1 for correct identification and 0 for wrong or unidentified bird species), bringing the maximum recognition score per respondent to twenty-two (Table 2). Although we had a seemingly small, non-random sample in that it was restricted to ages 12-15, we have no reason to doubt that it gives a good representative sample of Mushere children's bird knowledge.

\section{Results and Discussion}

Out of 56 children surveyed, 34 were boys (61\%) and $22(39 \%)$ were girls. About half of the children were 12 years old ( $\mathrm{n}=24 ; 14$ boys, 10 girls; $43 \%$ ), while 22 (13 boys, 9 girls; 39\%) were 13 years old, five $(9 \%)$ were 14 years old, and another five $(9 \%)$ were 15 year 
Table 2 Children's folk bird names generated from free-listing exercises organized according to their frequency of mention.

\begin{tabular}{|c|c|c|}
\hline Folk Name & Scientific Name & Common Name \\
\hline Mbul & Columbidae & Pigeons and Doves (Columbidae) \\
\hline Tidit & $\begin{array}{l}\text { Estrildidae, especially Lagonosticta } \\
\text { senegala (Linnaeus 1766) and Urae- } \\
\text { ginthus bengalus (Linnaeus 1766) }\end{array}$ & $\begin{array}{l}\text { Firefinches, especially the Red-billed } \\
\text { Firefinch and Red-cheeked Cordon- } \\
\text { bleu }\end{array}$ \\
\hline Mbulkan & $\begin{array}{l}\text { Columbidae: Treron calvus } \\
\text { (Temminck 1808) }\end{array}$ & African Green Pigeon \\
\hline Fyem & Falco tinnunculus (Linnaeus 1758) & Common Kestrel \\
\hline Yiyi or guguk & Strigidae/ Tytonidae & Owls including the barn owl \\
\hline Nayakar or kwom & $\begin{array}{l}\text { Pternistis bicalcaratus (Linnaeus } \\
1766 \text { ) }\end{array}$ & Double-spurred Francolin \\
\hline $\begin{array}{l}\text { Yerdang or dadak (children alone mostly } \\
\text { refer to it as dadak, a name unknown to } \\
\text { adults; yerdang literally means bird of tail, } \\
\text { referring to its long tail. Why children } \\
\text { choose a different name is unknown, as } \\
\text { they do not know what dadak means). }\end{array}$ & Colius striatus (Gmelin 1789) & Speckled Mousebird \\
\hline $\begin{array}{l}\text { Yerkong (literal: bird of bank, referring to } \\
\text { its hole-nesting behaviour along banks) }\end{array}$ & Merops bulocki (Vieillot 1817) & Red-throated Bee-eater \\
\hline Ngupiya & Bubulcus ibis (Linnaeus 1758) & Cattle Egret \\
\hline Nannan & Emberiza tahapisi (Smith 1836) & Cinnamon Rock Bunting \\
\hline Nilip & Euplectes franciscanus (Isert 1789) & Northern Red Bishop \\
\hline Keleng & Accipiter badius? (Gmelin 1788) & Shikra \\
\hline $\begin{array}{l}\text { "Canary" (children do not know its folk } \\
\text { name, surprisingly, it is known by its com- } \\
\text { mon name) }\end{array}$ & Crithagra mozambica (Müller 1776) & Yellow-fronted Canary \\
\hline Njakan & Ardeidae & Herons \\
\hline Gopang & Ptilopachus petrosus (Gmelin 1789) & Stone Partridge \\
\hline Ngoro & Corvus albus (Müller 1776) & Pied Crow \\
\hline Kuljem & Scopus umbretta (Gmelin 1789) & Hamerkop \\
\hline Ndibin or ndighim & $\begin{array}{l}\text { Ploceidae, especially Ploceus } \\
\text { cucullatus (Müller 1776) }\end{array}$ & $\begin{array}{l}\text { Weaverbird, especially known is the } \\
\text { village weaver. }\end{array}$ \\
\hline $\begin{array}{l}\text { "Bitree" (a name only used by children, } \\
\text { unknown to the adults) }\end{array}$ & Passer griseus (Vieillot 1817) & Northern Grey-headed Sparrow \\
\hline Tau & Nectarinidae & Sunbirds \\
\hline Jingjit & $?$ & $?$ \\
\hline Zar or jar & Buphagus africanus (Linnaeus 1766) & Yellow-billed Oxpecker \\
\hline Chilchap & Hirundinidae & Swallows \\
\hline
\end{tabular}

? = species unidentified and unknown *bats were continuously mentioned as birds by children, although they had no knowledge of any uniqueness of the bats; adults, however, mentioned that bats were a special category of "birds" because they are not considered true birds **both domestic chickens and ducks were classified as birds.

(continued on next page) 
(continued from previous page)

Table 2 Children's folk bird names generated from free-listing exercises organized according to their frequency of mention.

\begin{tabular}{lll}
\hline Folk Name & Scientific Name & Common Name \\
\hline${ }^{*}$ Ndin or shizhik & Chiroptera & Bats \\
Kadukul & $?$ & $?$ \\
Kajukut & $?$ & $?$ \\
${ }^{* *}$ Nishogor or koshokor & $?$ & Wild duck/domestic ducks \\
Pukul & Accipritidae & Eagles \\
Kakajukut & $?$ & $?$ \\
Bulguguk & $?$ & $?$ \\
Dudut & $?$ & $?$ \\
Dem & Numida meleagris (Linnaeus 1758) & Helmeted Guineafowl \\
Yer-am (yer=bird; am=water) & $?$ & Water bird (common name for all wa- \\
$* *$ Ko'o & Gallus gallus (Linnaeus 1758) & ter birds) \\
Nigiya & Necrosyrtes monachus (Temminck & Hooded Vulture \\
Gulak & 1823 ) & \\
Langlakap & Pycnonotus barbatus (Desfontaine & Common Bulbul \\
\hline
\end{tabular}

$?=$ species unidentified and unknown *bats were continuously mentioned as birds by children, although they had no knowledge of any uniqueness of the bats; adults, however, mentioned that bats were a special category of "birds" because they are not considered true birds **both domestic chickens and ducks were classified as birds. 
olds. Almost all respondents ( $\mathrm{n}=51,31$ boys, 20 girls; 91\%) were born in a Mushere village and had lived there while growing up, the remaining five (4 boys, one girl; 9\%) were not born in a Mushere village, but claimed to have spent their formative years in Mushere. This meant that our study sample was made up entirely of children who had spent all of their formative years in the Mushere community. Also, $98 \%$ of respondents claimed their parents were farmers, while the remaining $2 \%$ claimed their parents were both farmers and civil servants. Results from the free-list analysis (Table 1) revealed children's knowledge included primarily garden birds and species commonly found around their homes. Out of 38 folk names generated from the lists, we considered only 13 species to be culturally salient; these included species whose frequency of mention was $20 \%$ or more. The species with the highest frequency of mention was mbul (Doves [Columbia]: 92.9\% of respondents), followed by tidit (referring to both Redbilled Firefinch [Lagonosticta senegal] and Red-cheeked Cordon-bleu [Uraeginthus bengalis]: 78.6\%), and African Green-pigeon (Treron calvus: 57.1\%). Apart from these 13 species, all other bird species mentioned had frequencies below 20\%. A complete list of bird species mentioned and their corresponding scientific and common names, (BirdLife International Database Zone 2017) where known, is presented in Table 2, while a list of the bird species used in the picture elicitation exercise and children's recognition scores are presented in Table 3. Overall, the results revealed a relatively low TEK of birds in children, when compared with ethnobotanical knowledge results of children elsewhere (Grasser 2016; Lozada 2006; McDade et al. 2007; Quinlan et al. 2016; Zarger and Stepp 2004). However, when the results are compared with children's bird knowledge around the world, Mushere children are found to know a similar or greater number of birds as children elsewhere. For instance, a study of British primary school children's knowledge of birds revealed that $55 \%$ of children could not name three of Britain's most common garden species, while a quarter could not identify birds such as the Robin (Erithacus rubecula) and House Sparrow (Passer domestics), which are common and widespread and have been culturally salient in the UK (Smith 2016, Gosler 2017 Appendix 1). Another British study of children's nature knowledge (Balmford et al. 2002) revealed a similar trend, where children in primary schools between the ages of 4 and 11 years could hardly name common British plants and animals including birds, but could name precisely Pokémon characters from Pokémon flashcards. Likewise, in Switzerland, Lindemann-Matheis and Bose (2008) found that when over 6,000 young people (8-18 years) where asked to name organisms in their immediate environments, they could only name an average of five plants and six animals, and across all the age groups most of these were unspecified taxa such as birds, grasses and trees. Compared to these examples, the results from the present study might not be surprising, as they are consistent with a globally observed trend of declining children's bird knowledge. Indeed, Ballouard et al. (2011), Lindemann-Matheis and Bose (2008, 2002), Bebbington (2005), and Balmford et al. (2002) had made similar observations, remarking that the public's ability to identify organisms was limited.

Even though certain researchers (e.g., Bang et al. 2007; Patrick and Tunnicliffe 2011), claim that children from developing countries are usually more knowledgeable about nature and hold greater ecological understanding than children from developed countries, our results do not completely agree with this assertion. People's nature knowledge should be taken as being context-dependent: it might be true for some areas of the world, but not true for others. Patrick and Tunnicliffe (2011) observed that in countries where children and adults are not in touch with nature, there seems to be a generally low awareness about environmental issues and a general lack of interest, care, and even apathy for the environment, an assertion which our results substantiate.

None of the children we interviewed showed any ethno-ecological knowledge of birds beyond knowing a few local bird names. They were also limited in their knowledge of cultural uses and associations of birds. Most of the children (36\%) when asked could not describe any cultural use of birds, while $30 \%$ reported using birds as pets and selling some (Figure 1). It is possible that their understanding of the term "cultural use" may have affected their responses, since they seemed to perceive birds only in terms of importance rather than use. When asked for an example to state the importance of birds, eating birds was mentioned more; when asked to describe how birds are utilized it became harder to respond, despite the use of our Mushere interpreter. It may be that this was a culturally inappropriate way to ask the question, or it may be revealing an even deeper issue: for example, 
Table 3 List of birds used in picture elicitation exercise in the order they were presented to respondents and the corresponding recognition scores of boys and girls for each bird species. Note: Total score per respondent=22, Total number of respondents=56.

\begin{tabular}{|c|c|c|c|c|}
\hline Common Name & Scientific Name & $\begin{array}{l}\text { Total Recognition } \\
\text { Score for Species } \\
\text { (\%) }\end{array}$ & Males \% & Females $\%$ \\
\hline Scarlet-chested Sunbird & $\begin{array}{l}\text { Chalcomitra senegalensis (Linnaeus } \\
1766 \text { ) }\end{array}$ & 15 & 32 & 18 \\
\hline Speckled Mousebird & Colius striatus (Gmelin 1789) & 34 & 71 & 46 \\
\hline Double-spurred Francolin & Pternistis bicalcaratus (Linnaeus 1766) & 37 & 82 & 59 \\
\hline African Grey Hornbill & Lophoceros nasutus (Linnaeus 1766) & 5 & 12 & 5 \\
\hline Cinnamon-breasted Bunting & Emberiza tahapisi (Smith 1836) & 29 & 71 & 23 \\
\hline Black-crowned Tchagra & Tchagra senegalus (Linnaeus 1766) & 0 & 0 & 0 \\
\hline Stone Partridge & Ptilopachus petrosus (Gmelin 1789) & 10 & 26 & 5 \\
\hline Hooded Vulture & Necrosyrtes monachus (Temminck 1823) & 11 & 21 & 18 \\
\hline *Common Barn-owl & Tyto alba (Scopoli 1769) & 55 & 100 & 96 \\
\hline *Purple Heron & Ardea purpurea (Linnaeus 1766) & 42 & 77 & 77 \\
\hline$* *$ Village Indigobird & Vidua chalybeate (Müller 1776) & 5 & 9 & 14 \\
\hline *Laughing Dove & Spilopelia senegalensis (Linnaeus 1766) & 51 & 97 & 86 \\
\hline **Bronze Mannikin & Spermestes cucullata (Swainson 1837) & 1 & 0 & 5 \\
\hline *Red-billed Firefinch & Lagonosticta senegala (Linnaeus 1766) & 46 & 88 & 77 \\
\hline Yellow-fronted Canary & Crithagra mozambica (Müller 1776) & 23 & 62 & 23 \\
\hline${ }^{*}$ Cattle Egret & Bubulcus ibis (Linnaeus 1758) & 50 & 97 & 82 \\
\hline Hamerkop & Scopus umbretta (Gmelin 1789) & 34 & 62 & 59 \\
\hline Village Weaver & Ploceus cucullatus (Müller 1776) & 18 & 44 & 14 \\
\hline Pied Crow & Corvus albus (Müller 1776) & 28 & 59 & 36 \\
\hline African Green-pigeon & Treron calvus (Temminck 1808) & 16 & 44 & 5 \\
\hline Helmeted Guineafowl & Numida meleagris (Linnaeus 1758) & 3 & 3 & 9 \\
\hline${ }^{*}$ Northern Red Bishop & Euplectes franciscanus (Isert 1789) & 42 & 85 & 64 \\
\hline
\end{tabular}

*Notice only 6 species stand out in the bird recognition test with more than half of respondents from both groups recognizing them; notice especially how almost all respondents recognize the Barn Owl (Tyto alba) due the negative cultural belief and association **Also note how male scores are higher than females' in all except three major cases: The Village Indigobird, the Bronze Mannikin, and the Helmeted Guneafowl. Although in three other cases, scores are similar: Purple Heron, Blackcrowned Tchagra, and Hammerkop. 


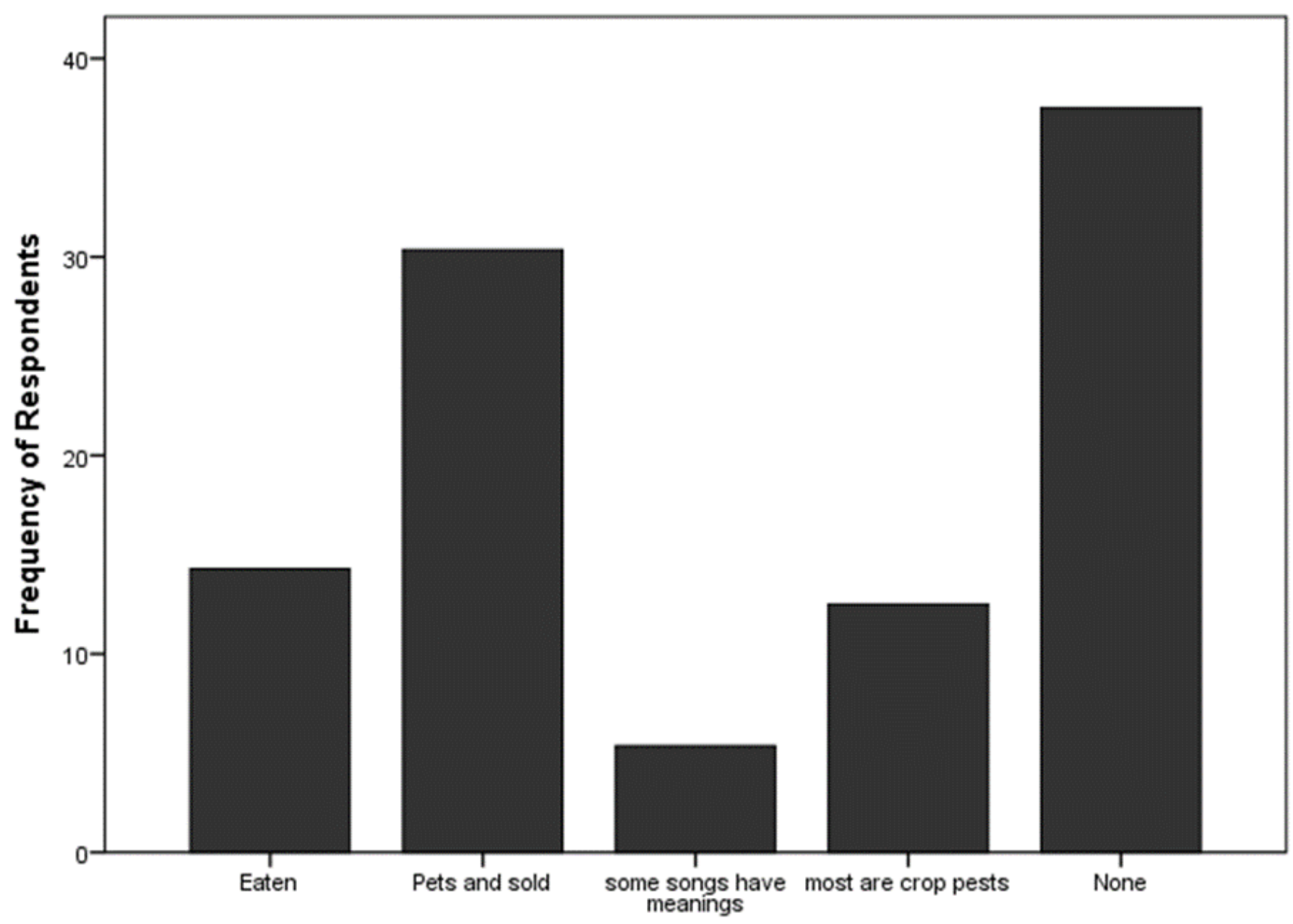

\section{Cultural uses}

Figure 1 Children's perceived cultural uses of birds.

that their unique perception of birds does not fit in a domain of cultural usefulness, in the sense that they interpret "useful". When we asked respondents what birds were kept as pets, only the Yellow-fronted Canary (Crithagra mozambica) was mentioned. It is also the only species regularly traded, although one child mentioned selling a Double-spurred Francolin (Pternistis bicalcaratus). Only 18 children (32\%) could recall a local bird story (and the same story was repeated all the time about mbul, the dove). No birdrelated folk song was recorded (except the call of mbul, the kukuruk-kukuruk, which they all gave as a folk song). This could suggest that birds have never been prominent in the Mushere culture and therefore do not feature in their folktales and songs, or that changes in lifestyle have affected the old tradition of story-telling as a method of preserving and transmitting information and knowledge. We believe that a combination of the two causes might be responsible for the observations, since neither could most adults, and especially elders, recall any birdrelated stories, claiming they had forgotten the stories as their grandchildren no longer spend time with them to encourage story telling. As Bisin and Verdier (2001) hypothesized on the economics of cultural transmission and the dynamics of preference: parents socialize and transmit only preferred cultural traits to their offspring, and birds in this case might not be a preferred domain for the Mushere. In addition, religious and cultural worldviews (cosmological worldviews) might be possible contributors to the observed low TEK of birds (see Houde 2007 for a 


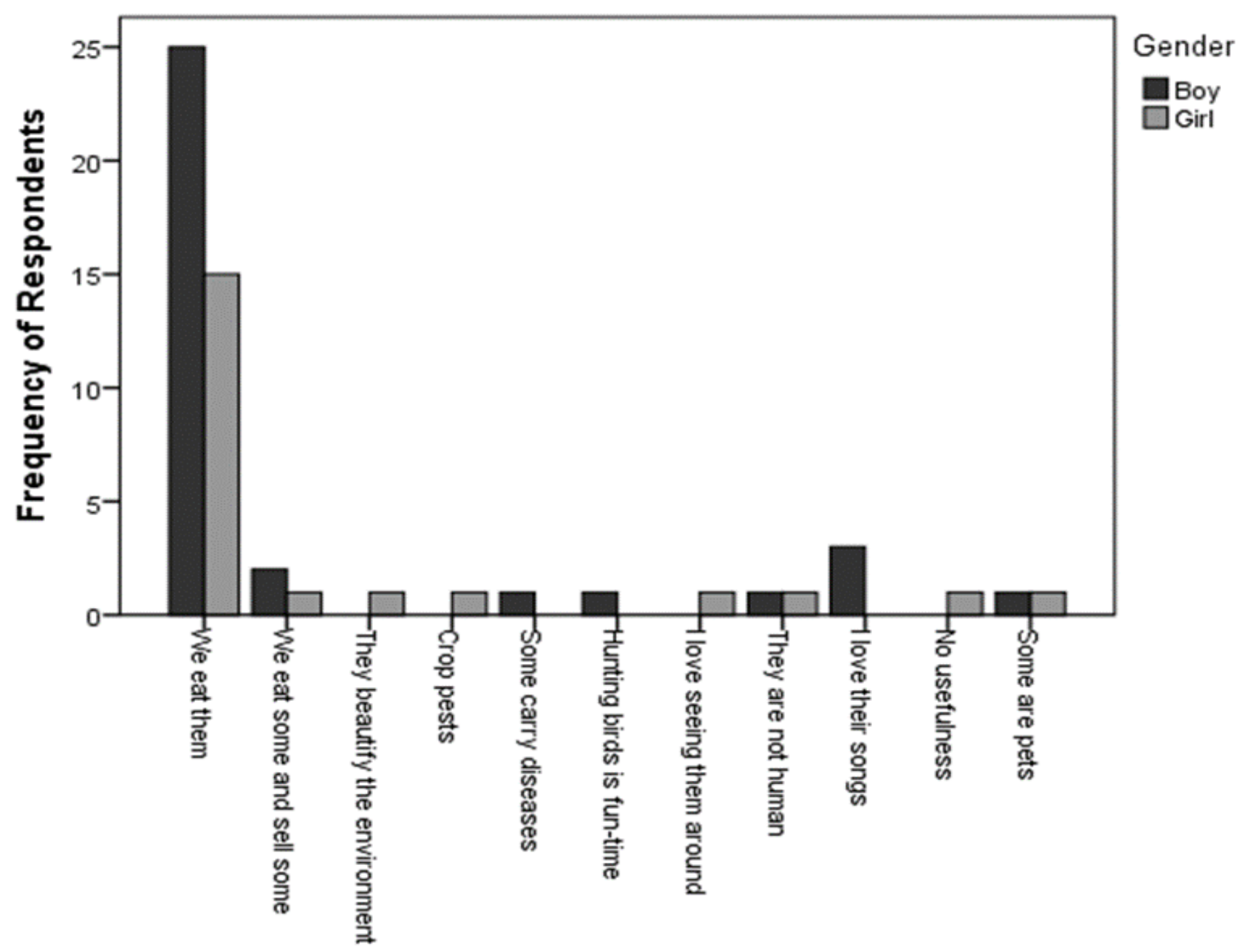

Perceptions on the Valuing of Birds

Figure $\mathbf{2}$ Children's gendered perceptions on why birds are/are not important.

detailed report on effects of these factors), but as these two factors were not part of the present study we cannot draw conclusions on this.

Another interesting observation was that certain birds mentioned in the free-lists were not recognized in the picture elicitation task (Table 3). While we accept that birds might be hard for children to identify from pictures, we do not think this was the case, as every bird picture was clear, and they showed no signs of difficulty in recognizing from pictures the birds they knew. It could be that the children know the names of certain birds, but cannot identify them in the field. One species in particular, the Blackcrowned Tchagra (Tchagra senegalus) went completely unrecognized by both male and female respondents, an observation similar to that of the adults who only recognized its call but not the bird itself. Although it was culturally salient in the adults' free-lists, it did not feature on children's free-lists even though some adults had cultural stories associated with the species. The bird is common in Mushere, as it appears in every visit in our records of Mushere birds. Adults also agreed that it is a common farm bird (as its Mushere name suggests yokmar. "bird of farm") mostly recognized by its call and considered a loquacious bird, but since we did not play birdcalls to the children, we could not verify whether they might have recognized it from its call.

Despite this limited bird knowledge, in response to the question, "Are birds important or not 


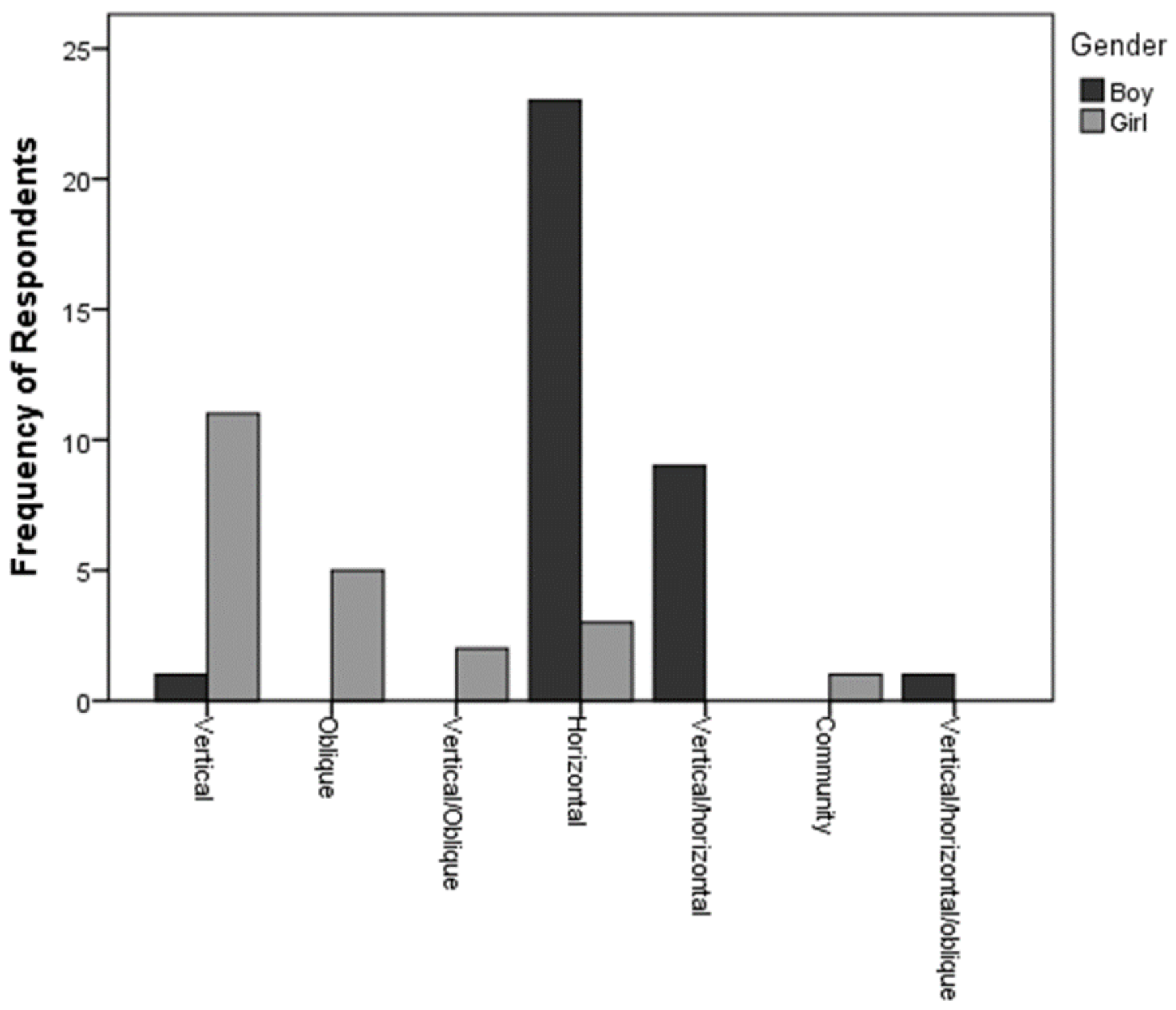

\section{Source of Learning}

Figure 3 Children's gendered reported sources of TEK Acquisition/Transmission.

important to you?" $50(89 \%)$ claimed that birds were important, five $(9 \%)$ thought birds were not important, and one $(2 \%)$ thought some but not all birds were important. When further asked, "Why do you think they are important or not important?" $73 \%$ (27 boys, 14 girls) thought birds were important because they serve as food ("we eat them"), 9\% (3 boys, 2 girls) claimed birds are important for their aesthetic values ("birds are beautiful, I love their songs") while $7 \%$ (1 boy, 1 girl) mentioned the harmful uses of birds ("they destroy crops, some cause diseases, they are destructive"). Further, 2\% (1 girl) reported that birds serve as companions ("they are pets"), $7 \%$ ( 3 boys, 1 girl) reported that birds are used for food/money ("we eat them, we sell some") while 5\% (1 boy, 2 girls) did not think birds were important due to anthropocentric reasons ("birds are not human, they have no usefulness"), Figure 2. Although children may have stated that birds were 
important because they were being cooperative to someone with an interest in birds, the responses were varied and we think these responses are interesting because they indicated other perceptions, and especially that some of the children regarded birds in terms of their aesthetic values, not only as food. It is important to state that the free-listing method may have been partly responsible for the low bird naming ability recorded here. It requires that an individual call to mind all the items within a given category of interest spontaneously and out of the normal context in which the species is encountered, so that the likelihood of forgetting many items known to the individual might likely be high. It is important to bear these in mind, therefore, when interpreting the results.

\section{How Do the Children Learn about Birds?}

Our results revealed that girls learned primarily through vertical and oblique transmission (one or both parents, one or both grandparents) while transmission was more horizontal for boys (older siblings and friends) although a few boys reported learning from their fathers, none reported having learnt about birds from his female relatives or friends (Figure 3). These gendered differences in transmission methods were statistically significant (Pearson ChiSquare $=32.71, \mathrm{df}=7, \mathrm{p}$-value $<0.001)$. All the boys we interviewed had catapults, which they use at playtime to hunt for birds, or shoot them for pleasure. Hunting birds is therefore a gendered activity, giving boys the advantage of knowing and encountering more birds than do girls. The boys in our sample shared how during such periods they learn about birds, from their older siblings and friends with whom they spend their playtime. By "comparing notes" when they make a catch, they learn about the various birds in their environment. Sometimes, however, they take the bird home, where older siblings or fathers help in identifying the birds. The most reported mode of TEK acquisition for boys was through oral transmission/practice, 30 (54\%), while transmission modes for most girls was through oral/observation, $20(36 \%)$. These reported modes of TEK acquisition by boys and girls differed statistically (Pearson ChiSquare $=37.41, \mathrm{df}=1, \mathrm{p}$-value $<0.001)$.

Girls claimed that they learned mostly from their mothers or grandmothers and sometimes their fathers by observation, especially when a bird comes to the house, or when they are out in the "bush" (referring to the woods) collecting firewood, or farming. They claimed that at such times, they have opportunities to learn from listening as adults converse about a bird or by asking questions when they see one. Girls' learning is therefore more passive than is that of the boys (Figure 2). This observation is comparable with the pattern Bonta (2013) observed in Honduras where hunting is a male domain, and therefore males knew more bird names than did females. Girls in his study encountered birds that were common around their homes, gardens, and other places such as rivers where domestic chores take them. They knew fewer bird names than did the males, but had more detailed knowledge of the activities of such birds than did the males who knew nothing about what birds were doing (Bonta 2013).

\section{Is Bird Knowledge Children's Knowledge?}

Overall, children's bird knowledge was limited. Whereas adults knew a little more than bird names from our previous findings (Pam et al. in prep), and could give some ecological and behavioral information about a few bird groups or species, children seemed to know nothing about the birds beyond the names. The difference in knowledge between adults and children differed significantly (Mann-Whitney U=3,236.50, S. E. $=436.18$, p-value < $0.05)$. The mean recognition score for girls was $8.23 \pm$ 3.3 SD, while boys had a mean recognition score of $11.32 \pm 3.2 \mathrm{SD}$; boys therefore had significantly higher recognition scores than girls (Pearson ChiSquare $=24.59, \mathrm{df}=12, \mathrm{p}$-value $<0.05)$. Further, testing of their free-listing ability showed no significant difference in knowledge between boys and girls (Pearson Chi-Square=14.67, $\mathrm{df}=8, \mathrm{p}$-value $>0.05$ ).

Although it could be argued that adults generally know more than children due to their age and experience, we think that bird knowledge in Mushere may not be children's knowledge. This limited knowledge in children could be because of a general ornithoapatheia (cultural indifference; see Mapes et al. 2000; Wasson and Wasson 1957; Peintner et al. 2013, for a similar cultural orientation regarding Fungi: mycophilia and mycophobia) observed in adults, whom children invariably rely on for knowledge acquisition, or because of a lack of interest in children themselves to learn about birds and nature, or a combination of both.

Our ethnographic data lend support to both hypotheses, as elderly Mushere respondents often expressed their indifference to birds, and commented 
also that children must be willing and interested in birds to want to learn about them. A few adults lamented that the young were less interested in nature these days, but more interested in endeavors that will fetch ready cash, and in schooling. Another explanation for the observed limited TEK might be through the theoretical framework for ethnobiological classification described by Hunn (1999), in relation to the importance of ecological salience, taxonomic salience, and size, but our data do not completely support all these models.

Ecological salience seemed to play an important role in the naming ability of children, as the two most salient bird groups (Estrildidae and Columbidae) were also the most frequently encountered birds in our inventory list of the Mushere. However, taxonomic salience also seemed to be a factor in children's naming ability, as they could name most of the twenty salient species, which adults had previously named, though this varied by gender. We do not however have sufficient evidence from our data to prove that size was a major factor in their recognition and naming of birds, as the recognition exercises were based on already identified salient bird groups/ species. Our studies of adult Mushere knowledge suggest however that size might not be a limiting factor in bird TEK here, but that TEK of birds might be driven more by a lack of cultural appreciation of birds, probably as a result of religious or cosmological worldviews (e.g., Houde 2007). This aspect will require further investigation.

Children usually learn from adults by adopting the attitudes and values they learn from them (Tuan 2012). However, growing up in a rural environment may not necessarily mean that children will automatically learn about nature if adults at home and school do not help them to learn and appreciate it (Tuan 2012). It has been shown that knowledge of nature is learned by children in an environment of social and experiential learning; being actively involved in out-door nature activities along with family and friends (Chawla 1988; Gallios et al. 2015; Gaskins 2010; Niskac 2013; Rogoff et al. 2007; Zarger 2010).

Hunn (2002) showed that learning natural history comes readily to children, particularly when there is reinforcement of what they are learning from older members of their community. The culture of the Mushere does not encourage much socialization between children and adults, as children and adults do not normally do much together, and learning mostly takes place in work environments, where birds may not be the objects of attention. Similar observations have been reported by Timyan (1988) and Law (1999), who observed that children in West Africa spend most of their day together, away from parents, and it is usually the role of older siblings both to play with, and care for, the younger children. What children will learn, and how they learn it will depend on the cultural and familial relationships that exist, which are also strongly influenced by the local maintenance systems (Gallios et al. 2015; Whiting and Whiting 1975) such as changes in the social, economic, and even biophysical environment from that which their parents experienced.

Adults in Mushere, as elsewhere in the world, are faced with the demands of a global economy and the desire to have their children receive formal education, which is seen as the "ticket" to a brighter and better future. TEK may no longer seem useful in such a context. Similarly, time spent in nature observing it might seem to be wasted since it is not directly linked to survival and maintenance, and sharing such knowledge with the younger generation might then not be considered worthwhile.

This takes us back to the central question: Can birds be used to encourage children in biodiversity conservation in Mushere? We argue that although there seems to be an indifference towards birds, it is possible to engage the Mushere through a birdfocused/nature discourse, as humans naturally have a sense of kinship with nature and children can easily be taught to appreciate nature (Tuan 2012).

This research forms part of a community-based conservation approach in the conservation efforts at Mushere, which include working with the communities to establish a community forest reserve in the Dulu-Mushere forest. We have started carrying out nature education activities, and sharing the fascinating life of birds with the children. It was a priceless experience watching the reactions of different individuals, both adults and children as they handled binoculars for the first time, and viewed birds through them! This is just one of the many methods we intend to use in the conservation work among the Mushere. We believe that a sustained approach in education, and generally presenting a different perspective on birds and the ecosystem services they provide, could help bring about an attitudinal change towards birds and nature generally, in addition to 
encouraging an appreciation for the Mushere's own linguistic and cultural connections with nature by providing contextualized nature education materials.

In a study comparing attitudes of adults and children towards wildlife in the United States, Kellert (1985) found that children had a greater natural tendency to be affectionate and interested in animals than did adults, whose attitudes were more utilitarian. Kellert also observed that those children who engaged in bird watching or hunting, or belonged to wildlife clubs, were more predisposed towards, and knowledgeable about, nature than were other children. These results suggest how it is possible for Mushere children to improve their present knowledge by building on what they already know, through nature educational activities adapted to reflect the local language, culture, and environment. If a child learns to enjoy nature through birds, this change can then affect others within her or his sphere of influence and potentially the world. As s/he grows up to be a nature-conscious individual, $\mathrm{s} /$ he will not only influence biophilia (nature-love) in others, but will treat nature as a gift and a responsibility, and not only as a resource.

\section{Acknowledgements}

The authors are grateful to all the Mushere children who shared their knowledge and to Mr Kopmak Dickbit Nguseng for his assistance in facilitating contacts with schools and parents. We thank also Pastor Haggai Ezekiel Kyesyil, our local field assistant and interpreter, for his invaluable assistance. We are grateful to all parents of participants and the participating schools, especially the head teachers and staff of Zokret Academy, Kawel and Unity Better Life College Kawel and the COCIN church leadership in the study areas for their support. We are grateful to Felice Wyndham for her invaluable contributions in the early planning of this work. We also thank Philip Hall of the Leventis Foundation for supplying binoculars to assist with ornithological work with the children. Thanks to EDEN Creation Care Initiative (ECCI) Nigeria for support with logistics. Finally, we should like to thank our respective institutions in ornithology and anthropology for the vision to support our work in applied ethnobiology.

\section{Declarations}

Permission for the work was granted by the University of Oxford's Central University Ethics Committee (CUREC Ref No: SSH_C1A_15_115).
Oral consent was obtained from the Community leaders, parents, schools and each participant. The A.G. Leventis Foundation and Schlumberger Foundation provided funding for the research to Pam as part of her doctoral work. We declare no conflicts of interest.

\section{References Cited}

Balmford, A., L. Clegg, T. Coulson, and J. Taylor. 2002. Why Conservationists Should Heed Pokémon. Science 295:2367-2367. DOI:10.1126/ science.295.5564.2367b.

Ballouard, J. M., F. Brischoux, and X. Bonnet. 2011. Children Prioritize Virtual Exotic Biodiversity over Local Biodiversity. Plos One 6:e23152. DOI:10.1371/journal.pone.0023152.

Bang, M., D. Medin and S. Atran. 2007. Cultural Mosaic and Mental Models of Nature. Proceedings of the National Academy of Science 104:13868-13874. DOI:10.1073/pnas.0706627104.

Bebbington, A. 2005. The Ability of A-level Students to Name Plants. Journal of Biological Education 39:6367. DOI:10.1080/00219266.2005.9655963.

Bernard, H. R. 2011. Research Methods in Anthropology: Qualitative and Quantitative Approaches. AltaMira Press, Walnut Creek, CA.

Bignante, E. 2010. The Use of Photo Elicitation in Field Research. Exploring Massai Representations and Use of Natural Resource. EchoGeo 11 [web page]. URL: http:// echogeo.revues.org/ index11622.html. Accessed on December 4, 2017.

BirdLife International Database [web page]. 2017. URL: http://datazone.birdlife.org/home. Accessed on December 4, 2017.

Bisin, A., and T. Verdier. 2001. The Econmics of Cultural Transmission and the Dynamics of Preferences. Journal of Economic Theory 97:298-319. DOI:10.1006/jeth.2000.2678.

Bonta, M. 2003. Seven Names for the Bellbird: Conservation Geography in Honduras. Texas A \& M University Press, College Station, TX.

Borgatti, S. P. 1996. ANTHROP AC 4.0. Analytic Technologies, Natick, MA.

Casagrande, D. G. 2004. Ethnobiology Lives! Theory, Collaboration, and Possibilities for the Study of 
Folk Biologies. Reviews in Anthropology 33:351-370. DOI:10.1080/00938150490889358.

Charles, C., and R. Louv. 2009. Children's Nature Deficit: What We Know and Don't Know. Children and Nature Network 1-32. Available at: http:// shinrin-yokusweden.se/wp-content/ uploads/2016/08/ childrens_nature_deficit_disorder_2009.pdf . Accessed on December 4, 2017.

Chawla, L. 1988. Children's Concern for the Natural Environment. Children's Environments Quarterly 3:1320.

Clements, R. 2004. An Investigation of the Status of Outdoor Play. Contemporary Issues in Early Childhood 5:68-80. DOI:10.2304/ciec.2004.5.1.10.

Cobb, E. 1969. The Ecology of Imagination in Childhood. In The Subversive Science: Essays Toward an Ecology of Man, edited by P. M. Shepard. D. Houghton Mifflin, Boston, MA.

Cocker, M. 2000. African Birds in Traditional MagicoMedicinal Use-A Preliminary Survey. Bulletin of African Bird Club 7:60-66.

Daugherty, J. W. D. 1978. Salience and Relativity in Classification. American Ethnologist 5:66-80. DOI:10.1525/ae.1978.5.1.02a00060.

Epstein, I., B. Stevens, P. McKeever, and S. Baruchel. 2006. Photo Elicitation Interview (PEI): Using Photos to Elicit Children's Perspectives. International Journal of Qualitative Methods 5:1-11. DOI:10.1177/160940690600500301.

Gallois, S., R. Duda, B. Hewlett, and V. Reyes-García. 2015. Children's Daily Activities and Knowledge Acquisition: A Case Study among the Baka from Southeastern Cameroon. Journal of Ethnobiology and Ethnomedicine 11:86. DOI:10.1186/s13002-0150072-9.

García, G. S. C. 2006. The Mother-Child Nexus. Knowledge and Valuation of Wild Food Plants in Wayanad, Western Ghats, India. Journal of Ethnobiology and Ethnomedicine 2:39. DOI:10.1186/1746-4269-2-39.

Gaskins, S., and R. Paradise. 2010. Learning Through Observation in Daily Life. In The Anthropology of Learning in Childhood, edited by D. F. Lancy, J. C. Bock, and S. Gaskins, pp. 85-118. AltaMira Press, Walnut Creek, CA.
Gosler, A. G. 2017. The Human Factor: Ecological Salience in Ornithology and Ethno-Ornithology. Journal of Ethnobiology 37:637-662. DOI:10.2993/0278-0771-37.4.637.

Grasser, S., C. Schunko, and C. R. Vogl. 2016. Children as Ethnobotanists: Methods and Local Impact of a Participatory Research Project with Children on Wild Plant Gathering in the Grosses Walsertal Biosphere Reserve, Austria. Journal of Ethnobiology and Ethnomedicine 12:46. DOI:10.1186/ s13002-016-01196-6.

Guimbo, I. D., J. G. Mueller, and M. Larwanou. 2011. Ethnobotanical Knowledge of Men, Women, and Children in Rural Niger: A Mixed-Methods Approach. Ethnobotany Research and Applications 9:235 -242. DOI:10.17348/era.9.0.235-242.

Hewlett, B. S., and L. L. Cavalli-Sforza. 1986. Cultural Transmission among Aka Pygmies. American Anthropologist 88:922-934. DOI:10.1525/ aа.1986.88.4.02a00100.

Houde, N. 2007. The Six Faces of Traditional Ecological Knowledge: Challenges and Opportunities for Canadian Co-Management Arrangements. Ecology and Society 12:34.

Hunn, E. 1999. Size as Limiting the Recognition of Biodiversity in Folkbiological Classifications: One of Four Factors Governing the Cultural Recognition of Biological Taxa. In Folkbiology, edited by D. S. Medin and S. Atran, pp. 47-69. MIT Press, Cambridge, MA.

Hunn, E. S. 2002. Evidence for the Precocious Acquisition of Plant Knowledge by Zapotec Children. In Ethnobiology and Biocultural Diversity, edited by J. R. Stepp, F. S. Wyndham, and R. K. Zarger, pp. 604-613. International Society of Ethnobiology, Athens, GA.

Jacobson, S. K., M. D. Mcduff, and M. C. Monroe. 2015. Conservation Education and Outreach Techniques. Oxford University Press, Oxford, UK.

Kellert, S. R. 1985. Attitudes Toward Animals: AgeRelated Development Among Children. Journal of Environmental Education 16:29-39.

DOI:10.1007/978-94-009-4998-0_3.

Kruetz, A. 2015. Children and the Environment in an Australian Indigenous Community. A Psychological Approach. Taylor and Francis Group, New York, NY. 
Law, J. 1999. Factors Affecting Language

Development in West African Children: A Pilot Study Using Qualitative Methodology. Child Care, Health, and Development 26:289-305.

Lindemann-Matthies, P. and E. Bose. 2008. How Many Species Are There? Public Understanding and Awareness of Biodiversity in Switzerland. Human Ecology 36:731-742. DOI:10.1007/s10745-0089194-1.

Lindemann-Mathies, P. 2012. "Loveable" Mammals and "Lifeless" Plants: How Children's Interest in Common Local Organisms Can Be Enhanced Through Observation of Nature. International Journal of Science Education 27:655-677.

DOI:10.1080/09500690500038116.

Louv, R. 2008. Last Child in the Woods: Saving Our Children from Nature-Deficit Disorder: Algonquin Books, Chapel Hill, NC.

Lozada, M., A. Ladio, and M. Weighandt. 2006. Cultural Transmission of Ethnobotanical Knowledge in a Rural Community of Northwestern Pategonia, Argentina. Economic Botany 60:374-385. DOI:10.1663/0013-0001(2006)60[374:CTOEKI] 2.0.CO;2.

Mapes C., F. P. Bandeira, J. Caballero, and A. GoesNeto. 2000. Mycophobic or Mycophilic? A Comparative Etnomycological Study between Amazonia and Mesoamerica. In Ethnobiology and Biocultural Diversity edited by J. R. Stepp, F. S. Wyndham, and R. K. Zarger. Proceedings of the Seventh International Congress of Ethnobiology, pp. 180-188. University of Georgia Press, Athens, GA.

Martínez-Rodríguez, M.-R. 2009. Ethnobotanical Knowledge Acquisition among Tsimane' Children in the Bolivian Amazon. University of Georgia Press, Athens, GA.

McDade, T. W., V. Reyes-García, P. Blackinton, S. Tanner, T. Huanca, and W. R. Leonard. 2007. Ethnobotanical Knowledge is Associated with Indices of Child Health in the Bolivian Amazon. Proceedings of the National Academy of Sciences 104:6134-6139. DOI:10.1073/ pnas.0609123104.

Medin, D. L., N. O. Ros, and D. G. Cox. 2006. Culture and Resource Conflict: Why Meanings
Matter, pp 108-173. Russell Sage Foundation, New York, NY.

Nikolaus, G. 2000. Bird Exploitation for Traditional Medicine in Nigeria. Malimbus 23:45-55.

Niskac, B. T. 2013. Children's Learning Through Observation in the Context of Work and Play. Anthropology Notebooks 19:77-96.

O'Brien, C. M. 2010. Do They Really "Know Nothing”? An Inquiry into Ethnobotanical Knowledge of Students in Arizona, USA. Ethnobotany Research and Applications 8:35-47. DOI:10.17348/era.8.0.35-47.

Pam, G., M. T. E. Hopkins, D. Zeitlyn, and A. Gosler. (In prep.) Who Cares About Birds? EthnoOrnithology of the Mushere People of NorthCentral Nigeria: An Assessment and Conservation Implications of Adult Bird Knowledge.

Patrick, P and S. D. Tunnicliffe. 2011. What Plants and Animals do Early Childhood and Primary Students Name? Where do They See Them? Journal of Science Education and Technology 20:630-642. DOI:10.1007/s10956-011-9290-7.

Peintner, U., S. Schwarz, A. Mešić, P-A. Moreau, G. Moreno, and P. Saviuc. 2013. Mycophilic or Mycophobic? Legislation and Guidelines on Wild Mushroom Commerce Reveal Different Consumption Behaviour in European Countries. Plos One 5:e63926. DOI:10.1371/ journal.pone.0063926.

Quinlan, M. B., R. J. Quinlan, S. K Council, and J. W. Roulette. 2016. Children's Acquisition of Ethnobotanical Knowledge in a Caribbean Horticultural Village. Journal of Ethnobiology 36:433456. DOI:10.2993/0278-0771-36.2.433.

Rogoff, B., L. Moore, B. Najafi, A. Dexter, M. Correa-Chávez, and J. Solis. 2007. Children's Development of Cultural Repertoires through Participation in Everyday Routines and Practices. In Handbook of Socialization, edited by J. E. Grusec and P. D. Hastings, pp. 490-515. Guilford, New York, NY.

Si, A. 2016. Ethnobiology. The Traditional Ecological Knowledge of the Solega: A Linguistic Perspective. pp. 97-99. Springer, Switzerland.

Singer, D. G., J. L. Singer, H. D'Agnostino, and R. DeLong. 2009. Children's Pastimes and Play in 
Sixteen Nations: Is Free-Play Declining? American Journal of Play 1:283-312.

Smith, R. 2015. The Telegraph. A Quarter of Children Cannot Identify Birds like Robins and Sparrow [web page]. URL: http:// www.telegraph.co.uk/news/earth/ environment/11568058/Childrens-knowledge-ofnature-is-dwindling-study-finds.html. Accessed on August 16, 2017.

Stross, B. M. 1973. Acquisition of Botanical Terminology by Tzeltal Children. In Meaning in Mayan Languages, edited by M. S. Edmonson, pp. 107-141. Walter de Gruyter, New York, NY.

Somnasang, P. and G. Moreno-Black. 2000. Knowing, Gathering and Eating: Knowledge and Attitudes about Wild Food in an Isan Village in Northeastern Thailand. Journal of Ethnobiology 20:197 -216 .

Timyan, J. 1988. Cultural Aspects of Psychosocial Development: An Examination of West African Childrearing Practices. Unicef 18:8-12.

Tongco, D. C. 2007. Purposive Sampling as a Tool for Informant Sampling. Ethnobotany Research and Applications 5:147-158.

Tuan, Y. 2012. Children and the Natural Environment. In Children and the Environment. Human Behaviour and Environment. Advances in Theory and Research Vol. 3, edited by I. W. Altman and J. F. Wohlwill, pp. 9-12. Plenum Press, New York, NY.

Turner, N. J., M. B. Ignace, and R. Ignace. 2000. Traditional Ecological Knowledge and Wisdom of Aboriginal Peoples in British Columbia. Ecological
Applications 10:1275-1287. DOI:10.1890/1051-0761 (2000)010[1275:TEKAWO]2.0.CO;2.

Wasson, V. and R. G. Wasson. 1957. Mushrooms, Russia, and History. Pantheon Books, New York, NY.

Weliange, W. S., R. A. Kolawole, N. S. Prasannajith, A. S. Afolabi, and E. C. Ameachi. 2015. Ethnoornithological Knowledge and Uses of Birds in Omiaro and Labaka Villages, Kwara State, Nigeria. Malimbus 36:41-54.

Whiting, B. B., and J. W. Whiting. 1975. Children of Six Cultures: A Psycho-Cultural Analysis. Harvard University Press, Cambridge, MA.

Williams, V. L., A. B. Cunningham, A. C. Kemp, and R. K. Bruyns. 2014. Risk to Birds Traded for African Traditional Medicine: A Quantitative Assessment. Plos One 9:e105397. DOI:10.1371/ journal.pone.0105397.

Wyndham, F. S. 2010. Environments of Learning: Rarámuri Children's Plant Knowledge and Experience of Schooling, Family, and Landscapes in the Sierra Tarahumara, Mexico. Human Ecology 38:87-99. DOI:10.1007/s10745-009-9287-5.

Zarger, R., and J. Stepp. 2004. Persistence of Botanical Knowledge among Tzeltal Maya Children. Current Anthropology 45:413-418. DOI:10.1086/420908.

Zarger, R. K. 2010. Learning the Environment. In The Anthropology of Learning in Childhood, edited by D. F. Lancy, J. C. Bock, and S. Gaskins, pp. 341-370. AltaMira Press, Walnut Creek, CA. 